\title{
Effects of Regular Intake of Green Tea on Nutrient Absorption, Serum Albumin and Organ Sizes of Alloxan- induced Diabetic Rats
}

\author{
Evelyn Njideka Bede \\ Department of Food Science and Technology, Federal University of Technology Owerri, Imo State, Nigeria
}

Email address:

njbede@gmail.com

To cite this article:

Evelyn Njideka Bede. Effects of Regular Intake of Green Tea on Nutrient Absorption, Serum Albumin and Organ Sizes of Alloxan-induced Diabetic Rats. International Journal of Nutrition and Food Sciences. Vol. 4, No. 5, 2015, pp. 535-540. doi: 10.11648/j.ijnfs.20150405.14

\begin{abstract}
The effects of regular intake of green tea on nutrient absorption, serum albumin and organ sizes were evaluated on alloxan-induced diabetic rats.. The rats were grouped into five treatment groups: NC (non-diabetic group fed with rat feed and water only), DC (diabetic group fed with rat feed and water only), CON1 (diabetic group fed with rat feed and $1 \mathrm{~g} / 100 \mathrm{ml}$ of brewed tea only), CON2 (diabetic group fed with rat feed and $2 \mathrm{~g} / 100 \mathrm{ml}$ of brewed tea only) and CON3 (diabetic group fed with rat feed and $3 \mathrm{~g} / 100 \mathrm{ml}$ of brewed tea only). Feed, water and tea were provided ad libitum for the respective groups for a period of 21 days. At the end of the treatment period, the apparent protein, calcium, iron and magnesium absorption of the groups were determined. The serum albumin as well as visual examination and measurement of organ sizes were also evaluated. The results showed that the diabetic groups $\mathrm{CON} 1, \mathrm{CON} 2$ and $\mathrm{CON} 3$ that took different concentrations of the green tea, did not show any significant change $(\mathrm{P}<0.05)$ in protein, iron and calcium absorption but had significant reduction $(\mathrm{P}<0.05)$ in magnesium absorption and serum albumin level when compared with the diabetic group DC that did not take the tea. There were also no significant change $(\mathrm{P}<0.05)$ between the organ sizes of the groups $(\mathrm{CON} 1, \mathrm{CON} 2$ and $\mathrm{CON} 3)$ and that of group DC.
\end{abstract}

Keywords: Green Tea, Nutrient Absorption, Serum Albumin, Organ Sizes

\section{Introduction}

Tea is the dried leaves of Camellia sinensis specie of the Theaceae family. It is one of the most popular beverages consumed worldwide with an annual production of three billion kilograms, of which $78 \%$ is black tea usually consumed by Western countries, $20 \%$ is green tea commonly consumed by Asian countries and $2 \%$ is Oolong tea consumed mainly by Chinese [1]. The health benefits of this ancient beverage regardless of the type have been documented $[2,3,4]$ However among all the tea types, the most significant health effects on humans have been observed with the consumption of green tea $[5,6]$.

Green tea has been considered to be anti-inflammatory, antiarthritic, antioxidative, antimutagenic, anticarcinogenic, neuroprotective and can also prevent cardiac disorders because of its cholesterol-lowering effects $[7,8,9,10]$. Epidermological studies have suggested that green tea consumption can prevent type 2 diabetes as well as lower blood glucose level. The ameliorative action of this tea on insulin resistance and blood glucose reduction, was associated with increased expression level of glucose transporter iv; enhanced basal and insulin-stimulated uptake of adipocytes and inhibition of intestinal glucose uptake by inhibition of the sodium-dependent glucose transporter of the intestinal epithelial cells $[11,12]$. Many diabetic and prediabetic people as well as people genetically predisposed to diabetes now consume much quantities of green tea on the bid to control their blood glucose.

However, despite, all the aforementioned health benefits associated with tea drinking especially the green tea due to its high polyphenol content [13], high intake of green tea has been associated with some adverse effects such as acute cytotoxicity of the liver cells $[14,15]$ and oxidation of DNA of hamster pancreas and liver [16]. Thus high intake of green tea may be detrimental to diabetic patients who use it in controlling hyperglycemia. In addition, a lot of controversies do exist on the mode of tea intake; "tea drinking with meal or without meal", owing to the polyphenols (catechin, epicatechin, epigallocatechin and gallates), tannins and 
caffeine contained in the tea which have also been shown to interfere with nutrient absorption, although the interference is termed to be complex and sometimes controversial or poorly understood $[17,18,19]$. On the bid to minimize or mitigate the supposed interference of tea components on nutrient absorption, especially the trace elements [20], many tea drinkers prefer drinking tea in-between meals instead of during meals. This also is not left without side effects such as nervousness, stomach upset and head ache etc. Hence, there is need to provide more evidence on the interference of tea components on nutrient absorption as well as investigate more on the toxicity of green tea at high intakes.

Thus the aim of this work is to investigate under diabetic condition, the effect of different concentrations of green tea on nutrient absorption, serum albumin and organ sizes.

\section{Materials and Methods}

\subsection{Sample Material}

The green tea sample used in this work was commercially produced and was bought from a supermarket in Owerri, Nigeria

\subsection{Qualitative Phytochemical Analysis}

Phytochemical screening of the green tea sample was carried out using standard procedures as described by [21, 22, 23].

\subsection{Animal Studies}

A total of 70 mature, male albino rats (Rattus norvegicus) of Wistar strain were sourced from Faculty of Veterinary Medicine, University of Nigeria, Nsukka, Nigeria. Upon arrival, the animals were allowed to acclimatize for 7days while been maintained on regular commercial rat feed (Vital feeds, growers; produced by UAC, Nigeria) and tap water. Tap water and feed were provided ad libitum throughout the period.

\subsubsection{Experimental Design}

A modified method of Eliakim [24] was adopted. After 7 days of acclimatization, the rats were fasted overnight. Diabetes was induced in 63 rats using a single dose of alloxan monohydrate $(125 \mathrm{mg} / \mathrm{kgbwt})$ which was given intraperitoneally. The remaining 7 rats received saline $(0.9 \%$ $\mathrm{w} / \mathrm{v} \mathrm{NaCl}$ ) injection which was also given intraperitoneally ( non-diabetic group ). Three (3) days after injection of alloxan, the fasting blood glucose concentrations of the rats were taken, (blood glucose at confirmation of diabetes) and only rats with blood glucose above $250 \mathrm{mg} / \mathrm{dl}$ were selected as diabetic rats used in this study. The fasting blood glucose of the non-diabetic group was also measured. The rats were grouped into five treatment groups: NC (non-diabetic group fed with rat feed and water only), DC (diabetic group fed with rat feed and water only), CON1 (diabetic group fed with rat feed and $1 \mathrm{~g} / 100 \mathrm{ml}$ of brewed tea only), CON2 (diabetic group fed with rat feed and $2 \mathrm{~g} / 100 \mathrm{ml}$ of brewed tea only) and CON3 (diabetic group fed with rat feed and $3 \mathrm{~g} / 100 \mathrm{ml}$ of brewed tea only). The tea was brewed in boiling water for two minutes after which it was allowed to cool to room temperature and then served. Feed, water and the tea were provided ad libitum for the respective groups for a period of 21 days. The average fasting blood glucose concentrations of the treatment groups were measured every week from the day of confirmation of diabetes (day 0) to the final day of administration of the tea ( day 21). The results of the treatment groups CON1, CON2 and CON3 were compared with those of the diabetic group DC and non-diabetic group $\mathrm{NC}$ that took tap water in place of the tea

At the end of the treatment period, the animals were fasted overnight, immobilized, their jugular veins severed and their blood samples collected for analysis of nutrient absorption and serum albumin concentration. The peritoneum of the animals were also stripped open and the organs (liver and Kidney) harvested for visual examination and organ measurements.

\subsubsection{Determination of Nutrient Absorption}

This was evaluated by determining the apparent absorption of protein, iron, calcium and magnesium in the serum of the treatment groups at the end of the treatment period; as described by Teco Diagnostics Reagent Set (Anaheim, USA).

\subsubsection{Determination of Serum Albumin} [25]

This was carried out as described by Friedman and Young

\subsubsection{Determination of Inflammation}

This was carried out by visual examination and measurement of the dimensions (length, breath, thickness) of the organs (liver and kidney) of the different treatment groups using a Venier caliper and micrometer screw gauge. The observable features and the organ sizes obtained from the groups that took the tea $(\mathrm{CON} 1, \mathrm{CON} 2, \mathrm{CO} 3)$ were compared with those of the groups that did not take the tea (NC, DC) to determine variations which served as index of inflammation and toxicity.

\section{Results and Discussions}

\subsection{Phytochemical Result}

The result of the phytochemical screening of the green tea sample revealed the presence of alkaloids, tannins, saponins, flavonoids, phytosterols, and cardiac glucosides which are known anti-nutritional factors that reduce nutrient intake, digestion, absorption and utilization as well as produce other adverse effects in biological systems [26, 27, 28].

\subsection{Results of Nutrient Absorption}

Literature has shown that increased absorption of nutrients under diabetic condition is caused by enhanced maximal rate of carrier-mediated transport or by alterations in the passive permeability properties of intestinal brush border membrane $[29,30]$. 
Thus the nutrient absorption effects of the green tea sample under diabetic condition, was determined by comparing the mean serum nutrient concentrations of the diabetic groups; $(\mathrm{CON} 1, \mathrm{CON} 2, \mathrm{CON} 3)$ that took different concentrations of the tea sample, with that of the diabetic group DC that did not take the tea. The mean serum iron and protein concentrations for the treatment groups $(\mathrm{NC}, \mathrm{DC}, \mathrm{CON} 1$, CON2, and CON3) are shown in Fig 1. Diabetic group CON1 which took $1 \mathrm{~g} / 100 \mathrm{ml}$ of the green tea had a significant reduction $(\mathrm{P}<0.05)$ in mean serum protein concentration when compared with that of the diabetic group DC that did not take the green tea; indicating inhibition of protein absorption. However, the diabetic groups CON2 and CON3 which took $2 \mathrm{~g} / 100 \mathrm{ml}$ and $3 \mathrm{~g} / 100 \mathrm{ml}$ of the green tea respectively showed increase in their mean serum protein concentrations but were not statistically different $(\mathrm{P}>0.05)$ from the mean value of the diabetic group DC. Also the diabetic groups that took different concentrations of the green tea (CON1, CON2 and CON3) had slight decrease in their mean serum iron concentrations but were not significantly different $(\mathrm{P}>0.05)$ from that of the diabetic group DC that did not take the green tea. This shows that the green tea did not have much effect on the iron absorption, supporting the findings of Zeyuan [20].

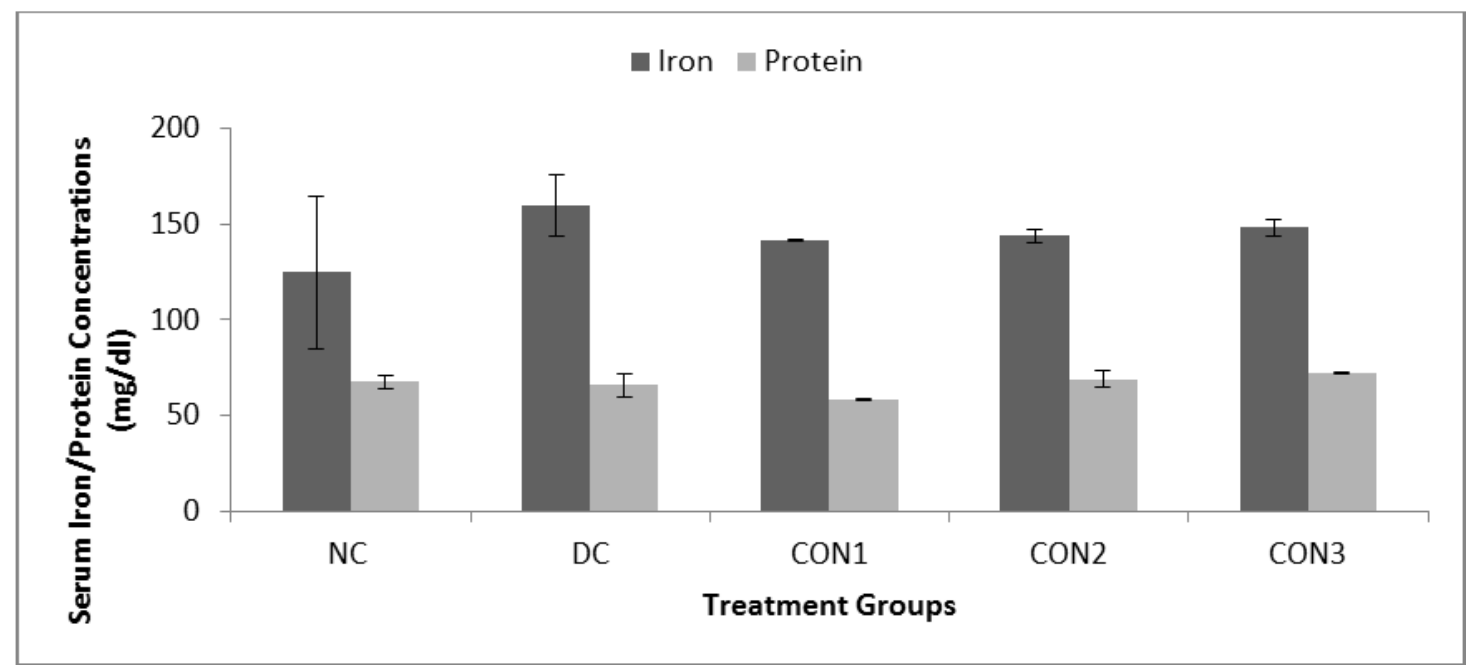

Fig. 1. Effect of different concentrations of green tea on mean serum iron/protein of the treatment groups at the end of the treatment period.

NC (non-diabetic group that took tap water and commercial rat feed),

DC (diabetic group that took tap water and commercial rat feed),

CON1 (diabetic group that took $1 \mathrm{~g} / 100 \mathrm{ml}$ of tea and commercial rat feed),

CON2 (diabetic group that took $2 \mathrm{~g} / 100 \mathrm{ml}$ of tea and commercial rat feed),

$\mathrm{CON} 3$ (diabetic group that took $3 \mathrm{~g} / 100 \mathrm{ml}$ of tea and commercial rat feed),

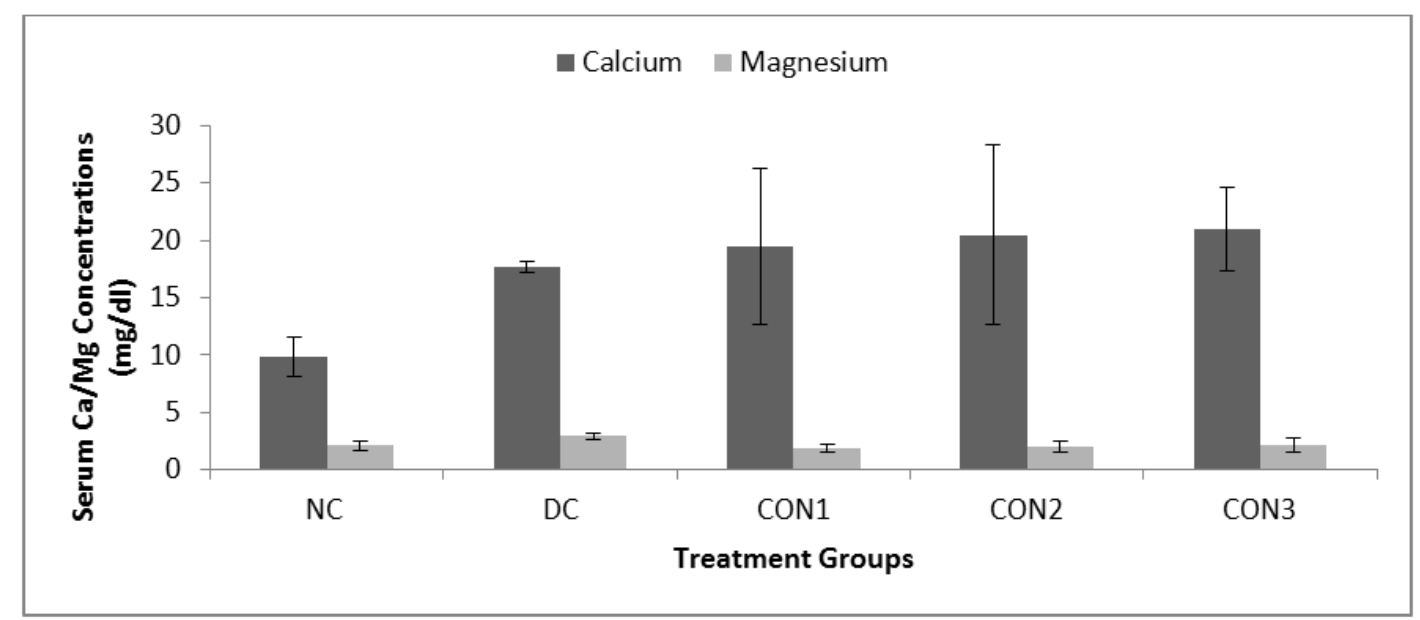

Fig. 2. Effect of different concentrations of green tea on mean serum calcium/magnesium of the treatment groups at the end of the treatment period.

NC (non-diabetic group that took tap water and commercial rat feed),

DC (diabetic group that took tap water and commercial rat feed),

CON1 (diabetic group that took $1 \mathrm{~g} / 100 \mathrm{ml}$ of tea and commercial rat feed),

CON2 (diabetic group that took $2 \mathrm{~g} / 100 \mathrm{ml}$ of tea and commercial rat feed),

$\mathrm{CON} 3$ (diabetic group that took $3 \mathrm{~g} / 100 \mathrm{ml}$ of tea and commercial rat feed), 
Figure 2 shows the results of the mean serum calcium and magnesium concentrations of the treatment groups that took different concentrations of the green tea. The diabetic groups CON1, CON2 and CON3 that took different concentrations of the green tea showed slight increase in their mean serum calcium concentrations when compared with the diabetic group DC that did not take the green tea. However, there was no significant difference $(\mathrm{P}>0.05)$ between the mean serum calcium values of the diabetic groups (CON1, CON2 and CON3) that took different concentration of the green tea and that of the diabetic group DC that did not take the green tea. This also agrees with the findings of Zeyuan [20] who showed that green tea did not cause significant changes in calcium and iron content of tibia. However, Craig [31] has shown that green tea can build bone strength, thus could be the reason for the slight increase in mean serum calcium concentrations of the diabetic groups CON1, CON2 and CON3 that took different concentrations of the green tea. However, the diabetic groups CON1, CON2 and CON3 that took different concentrations of the green tea showed reduction in their mean serum magnesium concentrations when compared with the diabetic group DC. However, the diabetic groups $\mathrm{CON} 1$ and $\mathrm{CON} 2$ that took $1 \mathrm{~g} / 100 \mathrm{ml}$ and $2 \mathrm{~g} / 100 \mathrm{ml}$ of the green tea respectively showed significant reduction in their mean serum magnesium concentrations $(\mathrm{P}<0.05)$ to that of the diabetic group DC that did not take the green tea.

\subsection{Result of Serum Albumin}

Serum albumin levels have been associated with development of toxicity $[32,33]$. Hyperalbuminemia is of little signifigance to health except in cases of dehydration while hypoalbuminemia is found to be caused by several factors such as reduced synthesis caused by liver diseases, increased catabolism as a result of inflammation or tissue damage, altered distribution between intravascular and extravascular space due to increased capillary permeability, abnormal losses caused by renal diseases (nephrotic syndrome, diabetes mellitus) [25]. Thus hypoalbuminemia is used clinically as one of the indicators of toxicity.

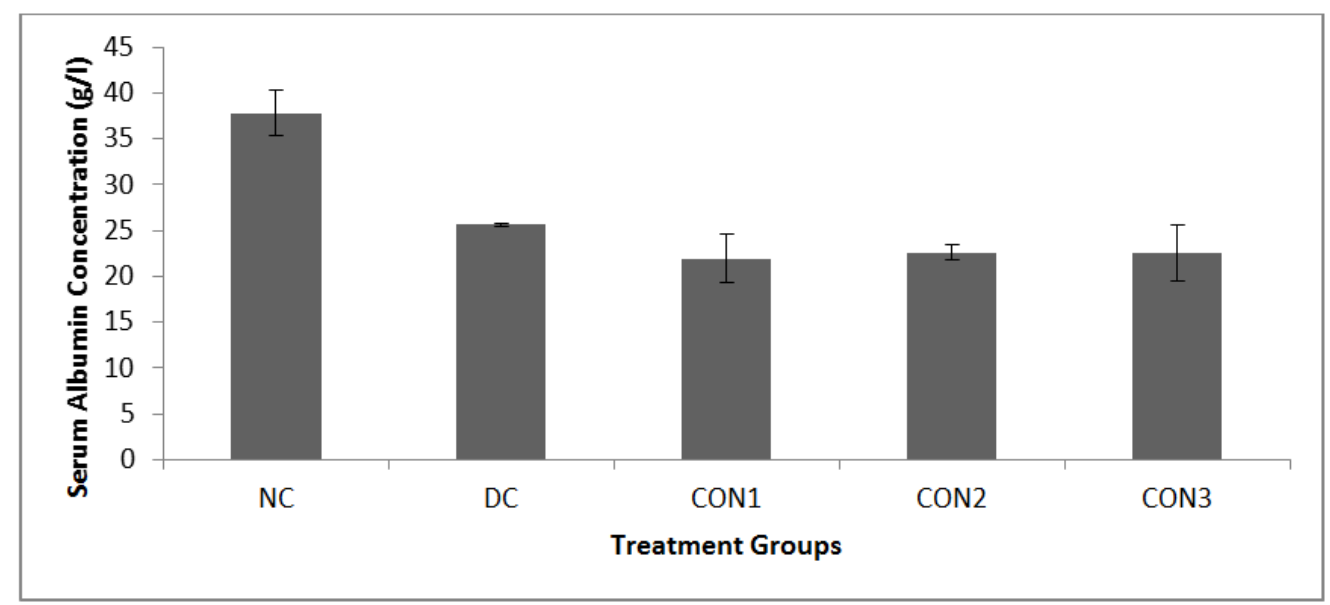

Fig. 3. Effect of different concentrations of green tea on mean serum albumin concentrations of the treatment groups at the end of the treatment period.

NC (non-diabetic group that took tap water and commercial rat feed), DC (diabetic group that took tap water and commercial rat feed), CON1 (diabetic group that took $1 \mathrm{~g} / 100 \mathrm{ml}$ of tea and commercial rat feed), CON2 (diabetic group that took $2 \mathrm{~g} / 100 \mathrm{ml}$ of tea and commercial rat feed), CON3 (diabetic group that took $3 \mathrm{~g} / 100 \mathrm{ml}$ of tea and commercial rat feed),

In this work therefore, in all the concentrations of tea intake studied, CON1, CON2 and CON3 (Fig.3), green tea caused significant reduction $(\mathrm{P}<0.05)$ in mean serum albumin concentration when compared with that of the diabetic group DC that did not take the tea, indicating some level of toxicity which could be attributed to two factors; the green tea they took or denial of water in these groups that took the green tea.

\subsection{Result of Inflammation}

Observable features in the organs of the treatment groups (CON1, CON2 and CON3) that took the green tea sample were, adhesion of the livers and the kidneys to the peritoneal wall, fusion of some liver lobes with the kidney, reduction in the number of the liver lobes and swelling of the livers and the kidneys. These features were also common in the diabetic group DC that did not take the green tea. The non-diabetic group NC did not manifest any of these changes.

The mean liver lengths and thicknesses of the treatment groups are shown in Table 1. The mean liver length and thickness of the non-diabetic group $\mathrm{NC}(3.95 \mathrm{~cm} ; 0.38 \mathrm{~cm})$ were significantly different $(\mathrm{P}<0.05)$ from that $(3.15 \mathrm{~cm}$; $0.87 \mathrm{~cm}$ ) of the diabetic group DC, indicating deformation of the livers of the diabetic group DC which could be caused by the metabolic disease; diabetes mellitus. In all the concentrations of tea intake considered, CON1 showed significant change in liver length and thickness when 
compared with the diabetic group DC while CON2 and CON3 did not. However, the significant increase in liver length showed by CON1 group could be what resulted to the significant decrease in liver thickness observed in the same group. There were no significant difference between the kidney lengths and thicknesses of the diabetic group DC and those of the groups (CON1, CON2, CON3) that took different concentrations of the tea.

Table 1. Mean organ lengths and thicknesses $(\mathrm{cm})$ of the treatment groups that took different concentrations of the green tea samples by the end of the treatment period.

\begin{tabular}{lllllll}
\hline Organs & NC & DC & CON & CON2 & CON3 & LSD \\
\hline Liver length & $3.95 \pm 0.15$ & $3.15 \pm 0.30$ & $3.60 \pm 0.17$ & $3.07 \pm 0.18$ & $3.21 \pm 0.02$ & 0.34 \\
Liver thickness & $0.38 \pm 0.01$ & $0.87 \pm 0.43$ & $0.35 \pm 0.04$ & $1.00 \pm 0.01$ & $0.62 \pm 0.23$ \\
Kidney length & $1.67 \pm 0.22$ & $1.62 \pm 0.12$ & $1.66 \pm 0.04$ & $1.62 \pm 0.02$ & $1.64 \pm 0.05$ \\
Kidney thickness & $0.63 \pm 0.04$ & $0.75 \pm 0.09$ & $0.76 \pm 0.01$ & $0.86 \pm 0.07$ & $0.74 \pm 0.05$ & 0.21 \\
\hline
\end{tabular}

LSD: Least Significant Difference

NC (non-diabetic group that took tap water and commercial rat feed),

DC (diabetic group that took tap water and commercial rat feed),

CON1 (diabetic group that took $1 \mathrm{~g} / 100 \mathrm{ml}$ of tea and commercial rat feed),

CON2 (diabetic group that took $2 \mathrm{~g} / 100 \mathrm{ml}$ of tea and commercial rat feed),

$\mathrm{CON} 3$ (diabetic group that took $3 \mathrm{~g} / 100 \mathrm{ml}$ of tea and commercial rat feed),

\section{Conclusion}

In general, under diabetic condition, green tea caused significant reduction in magnesium absorption but had little or no effect on protein, calcium and iron absorption. It also caused reduction in serum albumin concentration but no pronounced effect on organ sizes.

\section{References}

[1] C. S. Yang, J. M. Landau. Effects of tea consumption on nutrition and health. Journal of Nutrition 2000, 130:2409 2412 .

[2] V. M. Hegarty, H. M. May, K. T. Khaw. Tea drinking and bone mineral density in older women. American Journal of Clininical Nutrition 2000, 71:1003-1007.

[3] S. I. Trevisanato, Y. I. Kim. Tea and health. Nutrition Review 2000, 58:1-10.

[4] C. Schneider, T. Segre. Green tea: potential health benefits. American Family Physician 2009, 79(7):591-594.

[5] C. Cabrera, R. Artacho, R. Glimenez. Beneficial effects of green tea : a review. American Journal of Clinical Nutrition 2006, 25: $79-99$.

[6] S. M. Chacko, P. I. Thambi, R. Kuttan, I. Nishigaki. Beneficial effects of green tea: a literature review. Chinese Medicine 2010, 5: $13-22$.

[7] R. Benelli, R. Vene R, D. Bisacchi, S. Garbisa, A. Albini. Anti-invasive effects of green tea polyphenol epigallocatechin-3-galleate (EGCG), a natural inhibitor of metallo and serine proteases. Biological Chemistry 2002, 383:101-105.

[8] J. H. Weisburger, F. L. Chung. Mechanisms of chronic diseases causation by nutritional factors and tobacco products and their prevention by tea polyphenols. Food and Chemical Toxicology 2002, 40:1145 - 1154.

[9] T. M. Haqqi, D. D. Anthony, S. Gupta, N. Ahmad, M. S. Lee, G. K. Kumar, H. Mukhtar. Prevention of collagen-induced arthritis in mice by a polyphenolic fraction from green tea.
Proceedings of the National Academy of Sciences of the USA 1999, 96:4524-4529.

[10] O. Weinreb, S. Mandel, T. Amit, M. B. H. Youdim. Neurological mechanisms of green tea polyphenols in Alzheimer's and Parkinson's diseases. Journal of Nutritional Biochemistry 2004, 15:506 - 516.

[11] L. Y. Wu, C. C. Juan, L. S. Hwang, Y. P. Hsu, P. H. Ho, L. T. Ho. Green tea supplementation ameliorates insulin resistance and increases glucose transporter IV content in a fructose-fed rat model. European Journal of Nutrition 2004, 43:116 - 124.

[12] L. Y. Wu, C. C. Juan, L. T. Ho, Y. P. Hsu, L. S. Hwang. Effect of green tea supplementation on insulin sensitivity in SpragueDawley rats. Journal of Agriculture and Food Chemistry 2004, $52: 643-648$.

[13] K. Naghma, M. Hasan. Tea polyphenols for health promotion. Life Sciences 2007, 81:519 - 533.

[14] F. Takabayashi, S. Tahara, T. Kanerko, N. Harada. Effect of green tea catechins on oxidative DNA damage of hamster pancreas and liver induced by Nnitrosobis (2-oxopropyl) amine and/or oxidized soybean oil. Biofactors 2004, 21:335337.

[15] M. Schmidt, H. J. Schmitz, A. Baumgart, D. Guedon, M. I. Netsch, M. H. Kreuter, C. B. Schmidlin, D. Schrenk. Toxicity of green tea extracts and their constituents in rat hepatocytes in primary culture. Food Chemistry and Toxicology 2005, 43:307-314.

[16] Y. Itoh, T. Yasui, A. Okada, K. Tozawa, Y. Hayashi, K. Kohri. Preventive effects of green tea on renal stone formation and the role of oxidative stress in nephrolithiasis. Journal of Urology 2005, 173(1):271-275.

[17] P. Henry. Does green tea block iron \& B12? Http://www.livestrong.com/article/542844-does-green-teablock-iron-B12/ as retrieved on 4th July, 2015.

[18] E. A. Prystai, C. V. Kies, J. A. Driskell. Calcium, copper, iron, magnesium and zinc utilization of humans as affected by consumption of black, decaffeinated black and green tea. Journal of Academy of Nutrition and Dietetics 2015, 97(9): A64 - A68.

[19] B. Chilukoti. Drinking tea with or after meals- good or bad? http://www.thehealthsite.com /fitness/drinking-tea-with-orafter-meals-good-or-bad/ as retrieved on 17th July, 2015 
[20] D. Zeyuan, T. Bingying, L. Xiaolin, H. Jinming, C. Yifeng. Effect of green tea and black tea on the metabolisms of mineral elements in old rats. Biological Trace Element Research 1998, 65(1):75-86.

[21] A. Sofowara. Medicinal plants and traditional medicine in Africa. Spectrum books Ltd, Ibadan, Nigeria 1993. Pp. $289-$ 294.

[22] J. E. Trease, W. C. Evans. Pharmacognosy. (11th edn.). Brailliar Tiridel can. Macmillian Publishers, London 1989, Pp. $161-172$.

[23] J. B. Harborne. Phytochemical Methods. A guide to modern techniques of plant analysis. Chapman and Hall, London 1973, Pp $10-23$.

[24] C. F. Eliakim, A. I. Obri. Histological changes in the pancreas following administration of ethanolic extract of Alchornea cordifera leaf in alloxan-induced diabetic wistar rats. Nigerian Journal of Physiological Sciences 2009, 24(2): 153 - 155.

[25] N. Friedman, D. S. Young. Disease and clinical laboratory tests. 30th edition, AACC Press, London 1997, pp. $400-410$.

[26] K. E. Akande, U.D. Doma, H.O. Agu, H.M. Adamu. Major antinutrients found in plant protein sources: Their effect on nutrition. Pakistan Journal of Nutrition 2010, 9 (8): 827 - 832.

[27] G. O. Igile. Phytochemical and biological studies on some constituents of Vernonia amygdalina (compositae) leaves. Ph.D thesis, Department of Biochemistry, University of Ibadan, Nigeria 1996.
[28] K. O. Soetan. Pharmacological and other beneficial effects of antinutriional factors in plants. -A Review. African Journal of Biotechnology 2008, 7(25): 4713 - 4719.

[29] R. N. Fedorak, E. B. Chang, J. L. Madara, M. Field. (1987). Intestinal adaptation of diabetes. Altered Na-dependent nutrient absorption in streptozocin-treated chronically diabetic rats. Journal of Clinical Investigation 1987, 76(6): 245 - 249.

[30] L. Alan, N. D. Miller. Antioxidant flavonoids structure, function and clinical usage. Alternative Medicine Review. 1996, 1: $103-111$.

[31] W. J. Craig. New reports bolster bone-building benefits of green tea and foods rich in vitamin $\mathrm{D}$, calcium and protein. http:/www.vitalchoice.com/shop/pc/articles view.asp?id=284. As retrieved on 12th May 2014.

[32] O. Arrieta, R. M. Ortega, M. G. Sema-Thome, G. VillamievaRodriguez, D. Flores-Estrada, C. Diaz-Romero, C. M. Rodriguez, L. Martinez, K. Sanchez-Lara. Association of nutritional status and serum albumin levels with development of toxicity in patients with advanced non-small cell lung cancer treated with paclitaxel- cisplatin chemotherapy: a prospective study. http://www.biomedcentral.com/1471 2407/10/50 as retrieved on 18th April 2014.

[33] J. P. Nicholson, M. R. Wolmarans, G. R. Park. The role of albumin in critical illness. British Journal of Anasesthesia 2000, 85: $599-610$. 